\title{
Evolution of Viral Hepatitis: Role of Psychosocial Stress
}

\author{
Cristin Constantin Vere, Costin Teodor Streba, Ion Rogoveanu, \\ Alin Gabriel Ionescu and Letitia Adela Maria Streba \\ University of Medicine and Pharmacy of Craiova \\ Romania
}

\section{Introduction}

Psychological stress, as defined by modern science, appears when an individual balances existing threats, being real or imaginary, and after confronting them with his or hers current resources, and finds the later to be inadequate. In practice, this occurs when experiences are judged to be exceeding adaptive capacities by an individual, therefore over-soliciting the mental defense mechanisms and coping capabilities. The above definition and context excludes psychiatric disorders that may impair the integration capacities of an individual. In the following chapter, psychiatric disorders resulting from stressful events are also excluded. Chronic psychosocial stress is possibly the most complex and powerful harming agent, as its repetitive nature enables it to constantly follow a patient during the onset and the course of chronic disease.

The idea that stressful events in a life of a person can influence his or hers response to illness is an idea that appeared from ancient times, despite a lack of scientific evidence. However, recent advances in the field of psychoneuroimmunology led to a new perspective on the issue. The scientific community devoted its attention to designing experiments and studies in order to document the effects and interactions between psychological and physical stress, and the well-being of a living organism.

Within the last two decades, several studies revealed new interactions between endocrine response systems, such as the hypothalamic-pituitary-adrenal axis (HPA) or the sympathetic-adrenal-medullary (SAM) system, and various pathologies. Moreover, it has been proven that the central nervous system and especially the autonomous component exert regulatory effects on the immunity of the organism. The two regulatory bodies are deeply interconnected, numerous links at various levels critically determining the end function and outcome of the immune response.

Liver disease was demonstrated to be heavily influenced by perceived chronic stress during several human and animal studies. The effects of chronic viral hepatitis on liver parenchyma are well known, however the idea that real-life events, independent from the disease itself, can influence the course of this disease, is relatively new.

\section{Historical background}

From ancient times, the idea of the mind-body union has been deeply rooted into human beliefs. Religion as well as empiric medicine documented the relationship between the state 
of mind and the organic well-being of an individual. Hippocrates (460-377 BC) identified a link between negative emotions and incidents and somatic disorders, introducing the concept of psychosomatics. Socrates (469-399 BC) proclaimed as well that in order to cure an individual, the physician should take into account the physical illness or defect, as well as the spiritual, or as we would call it in modern times, the psychic component. Galen (AD 129199) further implemented the concept of negative emotions, such as anger, discontent or grief, as being "diseases".

However, this conceptual unity was contested during later years, the dispute being irrevocably solved by Rene Descartes (1596-1650) who proposed that the body is simply a machine that obeys the laws of physics, while the soul, which he placed in the pineal gland, was completely separated, and governed the mind of an individual. For the following 300 years all philosophical and medical writings approached the mind-body dichotomy from the same perspective.

Early twentieth century experiments, pioneered by Ivan Pavlov, William Beaumont and Steward Wolf, began to elucidate the relationship between the nervous system and different organs and their respective pathologies.

The last three decades of scientific research were crucial in the understanding of the intricate relationships between the

\section{The anatomical foundation and the mechanisms of the organic response to stress}

\subsection{The central stress mechanism}

Currently, it is widely acknowledged that a central stress mechanism exists, composed of different brain structures such as the lateral prefrontal cortex and the medial prefrontal structures, which in turn are connected with the amygdala and the paraventricular nucleus of the hypothalamus.

Output from these structures is projected onto the pontomedullary nuclei and the pituitary gland. The signals from this central system are conveyed to the sympathetic nervous system components regulated through autonomic neurotransmitters (epinephrine and norepinephrine). (Glaser R, 2005;)

The neuroendocrine component is represented by the functional axis composed from the hypothalamus, the pituitary and the adrenal glands (the HPA axis), regulated through circulating glucocorticoids. (Chrousos GP, 1992; Kemeny ME and Schedlowski M, 2007)

Pituitary hormones (prolactine and growth hormone) are released along with the adrenocorticotropic hormone (ACTH), neuropeptide Y (NPY) and opioids are actively released during stressful events. They directly influence antibody as well as cellular mediated immune response. ((Malarkey and Mills, 2007; Blalock and Smith, 2007)

All structures of the immune system receive sympathetic noradrenergic innervation, while B and $\mathrm{T}$ cellular lines express beta and alpha adrenoreceptors. (Kelley et al., 2007) The production and release of various cytokines and the circulation of leukocytes are also influenced by adrenaline and noradrenaline, neuromediators which are increasingly secreted during stress response. This increased sympathetic response stimulates the functions of the next major component in the stress response mechanism, the HPA axis, which in turn secretes elevated quantities of glucocorticoids, thus impairing the immune response. (Glaser and Kiecolt-Glaser, 2005) 


\subsection{The hypothalamic-pituitary-adrenal axis, glucocorticoids and the sympathetic nervous system}

The HPA axis represents, as stated above, the functional and anatomical system that regulates glucocorticoid secretion, playing a major role in the adaptive response of a normally-functioning organism. It is under direct neural control, receiving sympathetic innervation through short and long feedback circuits from the hypothalamus and other central structures.

Hence, it is deeply interconnected with the systemic and sympathetic adrenomedullary systems, both key components of the stress system, collaborating for the maintenance of basal homeostasis. The corticotrophin-releasing hormone $(\mathrm{CRH})$ and noradrenergic neurons of the central stress system are in close relation through a two-way feedback mechanism (Sanders VM and Kavelaars A, 2007) that assures inter-regulated levels of production of norepinephrine and CRH. (Sawchenko PE et al, 1993)

The hypothalamus represents the main regulatory structure of the HPA axis. It balances glucocorticoid secretion through the release of $\mathrm{CRH}$ and arginine vasopressin (AVP), with proinflammatory effects. These mediators are released in inflammation areas, while plasmatic concentrations remain low, thus proving their local effect in the inflammatory process. (Karalis $\mathrm{K}$ et al, 1991) The hypothalamic activity is up-regulated by the serotoninergic and cholinergic systems, and its activity is inhibited by the opioid-peptide and the gamma-aminobutiric acid-benzodiazepine systems existing at cerebral level. Substance $\mathrm{P}$ stimulates the central noradrenergic system, while inhibiting hypothalamic CRH-secreting neurons. (Culman J et al, 1993; Larsen PJ et al, 1993; Jessop DS et al, 1992) Hormones secreted by the adrenal medulla, such as corticotrophin, are the most important factors that regulate the secretion of glucocorticoids by the HPA. (Hinson JP. 1990; Calogero AE et al, 1992)

Secreted glucocorticoids regulate T-helper- 1 and 2 responses to viral infection by inhibiting the production of Interleukin 12 (IL-12) and Tumor Necrosis Factor Alpha (TNF Alpha). Several other interleukines (IL), such as IL-2 and cytokines IL-10 and IL-4 are stimulated through their actions. All these exert a pro-inflammatory role and occur under the influence of stress-related mechanisms. (Glaser and Kiecolt-Glaser, 2005).

Glucocorticoids also cause resistance to cytokines and stimulate eosinophil apoptosis, inhibit adhesion molecules and their specific receptors expressions (Cronstein BN et al, 1992) and exacerbate the acute phase reaction (Hirano $T$ et al, 1990). Pituitary hormones such as corticotrophin and especially beta-endorphin increase the immune response level and facilitate local inflammatory activity, (Bateman A et al, 1989) along with having analgesic effects (Schafer M et al, 1994).

\subsection{The HPA axis role in acute and chronic liver inflammation}

As already stated above, the activation of the HPA axis represents a key element of the normal response to stressor factors. The end result of this stimulation is the active secretion of glucocorticoids from the adrenal cortex, which is a natural process designed to improve survival chances in a fight-or-run scenario, usually associated with the notion of "exterior stress". This process, however, is involved in the control of the inflammatory response, which, in turn, can also interact by stimulation of the vagal afferents and thus activation of the HPA axis. 
Patients with chronic liver diseases, such as viral hepatitis, express delayed cortisol clearance and altered cortisol binding at plasma level. Elevated plasma cytokine levels are common in chronic inflammatory diseases, and chronic exposure to high levels of circulating cytokines is associated with HPA axis failure or dysfunction. (Turnbull AV and Rivier CL, 1999)

Experimental data suggest that chronic liver injury results in elevated TNF-alpha and IL-6 levels, as well as more specific cellular alterations at hypothalamic level, such as mRNA depletion and impaired protein expression resulting in decreased levels of secreted CRH, which in turn impairs the activation of HPA axis mechanisms. (Swain MG et al, 1993) Thus, lower levels of circulating hormones, consecutive to the independent action of an exterior stressor, may be a promoter of hepatic inflammation, concomitant to the usual viral effects.

Acute inflammatory injury of the liver in a rodent model resulted in the rapid activation of the HPA axis, with consecutive rises in circulating glucocorticoid (GC) levels. When the physiological effects of GCs are inhibited, the inflammatory response is enhanced, resulting in an increase mortality rate. (Swain MG et al, 1999) This in turn can be prevented by the administration of exogenous GCs. (Swain MG, 2000) The protective effect of GCs can partially be attributed to the fact that they mediate the synthesis and release of IL-10 at hepatic level, specifically by the liver-specific macrophage system, the Kupffer cells. They also produce a number of inflammatory mediators, such as IL-1, IL-6, TNF-alpha and the nitric oxide (NO), all of them up-regulated during liver inflammation. These effects are attributed to indirect mechanisms, as they interfere with the production of proinflammatory transcription factors such as (NF)-kB and the activator protein AP-1, or to direct mechanisms which operate at the level of mRNA stability and gene transcription.

Liao et al (Liao et al, 1995) studied the effects of corticosterone, at both normal and stress levels, on an isolated perfused rat liver. He observed that the GC increased the release of TNF-alpha and IL-6. Later studies provided evidence that psychological stress itself can have the exact effect, possibly by following the same pathways. (Tjandra K et al, 2001) The hepatic levels of inflammatory cytokines and compounds are differently influenced by GCs, as TNF-alpha seems to be the first to be altered, followed by IL 1 and IL 6 .

The hepatitis $C$ virus was directly linked to the recruitment of cellular effectors implicated in liver inflammation, during viral disease. Chemokines, being important mediators of liver inflammation, experience an increased expression during $\mathrm{HCV}$ infection. As dexamethasone, synthetic GC is routinely used in pretreatment phases, and was shown to attenuate endotoxins and cytokine expression of chemokines in immune cells during liver inflammation, we can suggest a theoretical link between stress-levels of endogenous GCs and chemokine levels during viral hepatitis.

Another critical component of the immune system is represented by T cells. In the liver, they are actively involved in the initiation, propagation and maintenance of the inflammatory disease. GCs were proven to specifically interact with T-cell proliferation in the liver, adrenal steroids being regulators of the T helper (Th) lymphocyte cytokine secretion. Many hormones that circulate in plasma as inactive forms are transformed into their active forms within the liver. Activation of the HPA axis under stress impairs the release of Th1 cytokines, thus shifting the profile towards Th2 dominance, as documented by Iwakabe et al (Iwakabe K et al, 1998) in a restrain-stress study on a rodent model. 
Circulating GCs induce T cell apoptosis. During the course of viral hepatitis, increased GCs levels at a hepatic level, following HPA activation, correlate with lower levels of activated Tcells at the same level.

Tamada et al (Tamada $\mathrm{K}$ et al, 1998) proved that administration of dexamethasone increases production of IL-4 hepatic natural killer (NK) 1.11-positive T cells, demonstrating that this cellular line is resistant to apoptosis induced by GCs. This study comes to support the theory that HPA may actively regulate the Th1/Th2 balance during acute or chronic stress exposure.

Proliferation of liver natural killer T (NKT) cells and the up-regulation of the Fas antigen on hepatocytes follow the increased GC production by the HPA axis. This conclusion is supported by research conducted by Chida and his team (Chida Y et al, 2004; Chida Y et al, 2006), who induced physical and psychological stress to rats by inescapable foot-shock.

Restrain stress, another standardized method of assessing psychophysical stress in animal studies, was found to increase the proportion of NK cells in the mouse liver through increased HPA activity and higher than normal GC concentrations. (Shimizu et al, 2000) Recent studies shown that monocyte chemotactic protein (MCP 1) and macrophage inflammatory protein (MIP 2) distribute NK cells along with other chemokines, thus suggesting that GCs may influence this sub-population through down-regulation of these substances (Kawakami K et al, 2001; Faunce DE et al, 2000)

Neutrophils are important in the early phases of hepatic inflammation. Circulating GCs have an inhibitory effect on neutrophil recruitment, as they down-regulate the expression of adhesion molecules, thus impairing chemotaxis.

\subsection{The parasympathetic nervous system and hepatic inflammation}

Recently, the main component of the parasympathetic feedback loop-mechanism that regulates liver inflammation was identified to be the "cholinergic anti-inflammatory pathway", this theory stating that efferent nerve fibers exist, supplementing the normal afferent pathways that sent information to the central nervous system from the hepatic site. Several cytokines such as IL-1 beta and TNF alpha seem to be implicated in the transduction process. In an in vivo macrophage culture, efferent vagus nerve was found to inhibit TNF alpha by releasing acetylcholine, when stimulated by endotoxins. This effect was proven to be dependent to nicotine acetylcholine receptor alpha 7 subunit (Borovikova LV et al, 2000; Wang $\mathrm{H}$ et al, 2003; Chida et al, 2006).

Several studies on transplanted and denervated livers show that inflammatory and immune components are severely impaired by the lack of sympathetic and parasympathetic innervations.

Growing evidence that anti-stress therapies known in traditional and standard medicine seem to stimulate the vagal influence on the liver, thus decreasing the immune response. (Zachariae R et al, 2001; Lux G et al, 1994)

\section{The influence of psychosocial stress on viral hepatitis}

Not many clinical studies evaluate the relationship between viral hepatitis B or C and stress response in a real-life setting. A number of studies did however underline the different mechanisms between the primary anatomical and functional systems in the human body and the intrinsic mechanisms regulating hepatic inflammation, the main morphological change encountered during the course of viral liver infection. 
Nagano et al (Nagano J et al, 2004) indicated in a clinical trial that a possible correlation exists between psychosocial stress and the severity of chronic hepatitis C. His team assessed levels of perceived stressor events through standardized stress questionnaires specifically designed to also provide information regarding personality types. Type 1 personality subjects are prone to disease due to the nature of their personal traits, being likely to be affected throughout chronic stress. Both type 1 personality traits as well as psychosocial stress positively correlated with the severity of chronic hepatitis C. Stress levels were assessed using items from the Grossarth-Maticek theory, which states that type-1 personality subjects are prone to developing chronic diseases. The severity of chronic hepatitis C was assessed through the levels of ALAT, platelet counts, albumin and total bilirubin levels, resulting two hepatitis groups and one cirrhosis group, containing those patients that exhibited signs of this pathology. Platelet count and serum albumin levels were positively correlated with levels of stress, and also proved to be good assessors for the severity of chronic hepatitis. ASAT values were strongly correlated with stress levels and type 1 personality types, thus establishing a connection between stress and the severity of chronic hepatitis C.

A link between chronic hepatitis B and depression scores and psychosocial stressors were assessed in a group of $50 \mathrm{HbsAg-positive} \mathrm{Korean} \mathrm{immigrants.} \mathrm{(Kunkel} \mathrm{et} \mathrm{al,} \mathrm{2000).}$ Depression scores, psychosocial factors and social support were evaluated and compared with biological markers of liver dysfunction, including hepatic transaminases, albumin levels and prothrombin times. These routine clinic follow-up values were correlated with scores obtained from short form Beck Depression Inventory questionnaires. Higher scores were significantly associated with elevated levels of transaminases; however albumin and PT levels did not correlate with stress scores.

Psychological implications of hepatitis $C$ virus diagnosis were evaluated by a number of studies. Muzaffar et al (Muzaffar L et al, 2005) proved that the diagnosis of HCV is considered more stressful than divorce or material loss or house relocation. His study of 98 patients infected with hepatitis $\mathrm{C}$ and 100 controls compared stress and anxiety levels regarding the diagnosis of $\mathrm{HCV}$ with other life-changing events including death of a close relative, loss of marital or material status or move to another city.

A study performed by Laurent Castera (Castera L et al, 2006) concluded that the psychological impact of chronic hepatitis $\mathrm{C}$ and emotional burden of such diagnoses are considerable, even when liver disease is insignificant.

\section{Psychosocial stress and vaccination against hepatitis $B$}

Hepatitis B currently represents a major health burden in many areas around the globe. The possibility of an effective vaccination is vital for controlling the effects hepatitis B viruses may have on exposed populations. Current studies estimate that a proportion of over $90 \%$ of the healthy subjects respond well to vaccination; however, the remaining $10 \%$ may not possess protective antibody titers at the end of the vaccination period. (Zajac BA et al, 1986) Chronic environmental stress exposure is common in several social settings, such as academic mediums which require extensive examination periods, unfulfilled marriages or job-related distress. These situations were shown to have a negative impact on all components of the immune response. This relationship can best be described by studying the effects stressors have on vaccination outcome, as this procedure clearly reflects the efficiency of the innate immune system against disease. 
Clinical studies which take into account stress exposure when assessing vaccination protection against hepatitis B are especially useful both for quantifying the effects of psychological stress on the immune response, and naturally for determining the optimum clinical settings for a successful vaccination campaign.

Burns et al (Burns VE et al, 2002) evaluated the stress and coping level of 265 first-year medical school undergraduates who completed the standard three-dose recombinant hepatitis B vaccination program. Test questionnaires were given to the participants, assessing life events of the past 12 months as well as coping types through the brief cope questionnaire and a short survey on individual health behaviors. Then their serum antibody levels were determined quantitatively. They found significant relations between stress questionnaire scores and antibody titers, while determining that coping and acceptance coping are significant predictors for antibody status. Life events exposure, sleep duration and physical exercises also proved to significantly improve antibody status postvaccination.

Another study (Marsland AL et al, 2006) examined 84 graduate students who received standard hepatitis B vaccination series. Subjects underwent a battery of questionnaires, and blood samples were evaluated. Their results showed that higher scores, measuring a positive dispositional affect (thus a sense of well-being and fulfillment), positively correlated with greater antibody response to hepatitis B vaccination. Physical activity also proved to provide a protective role.

The general consensus of these studies is that further studies should overcome obvious limitations such as retrospective design or small cohorts, and that experimental models can be devised in order to assess antibody status after hepatitis $B$ vaccination.

\section{Conclusion}

Current evidence proves a definite link between psychosocial stress levels and the status of liver hepatitis. The effects on the immune response ultimately lead to an exacerbation of the inflammatory response at hepatic level.

Recent advances were made in understanding the complete interactions between stress, neuroimmunomodulation and ultimately the onset and progress of viral infections.

Clinical implications are profound, as translational studies deciphering intrinsic cellular mechanisms and pathways lead the way to a better understanding of viral liver infection, thus improving the standard of care in this pathology.

Further studies are needed in order to fully understand the complex interactions between the social environment and chronic viral hepatitis.

\section{References}

Bateman A, Singh A, Kral T, Solomon S. The immunehypothalamic-pituitary-adrenal axis. Endocr Rev 1989; 10:92-112.

Borovikova LV, Ivanva S, Zhang $M$ et al. Vagus nerve stimulation attenuates the systemic inflammatory response to endotoxin. Nature 2000; 405: 458-62.

Blalock, J.E., Smith, E.M., 2007. Conceptual development of the immune system as a sixth sense. Brain Behav. Immun. 21, 23-33.

Burns VE, Carroll D, Ring C, Harrison LK, Drayson M. Stress, coping, and hepatitis B antibody status. Psychosom Med 2002; 64: 287-293 
Calogero AE, Norton JA, Sheppard BC, Listwak SJ, Cromack DT, Wall R, Jensen RT, Chrousos GP. Pulsatile activation of the hypothalamic-pituitary-adrenal axis during major surgery. Metabolism 1992; 41: 839-845.

Castera L, Constant A, Bernard PH, de Ledinghen V, Couzigou P. Psychological impact of chronic hepatitis C: Comparison with other stressful life events and chronic diseases. World J Gastroenterol 2006; 12(10): 1545-1550

Chida Y, Sudo N, Sonoda J, Sogawa H, Kubo C. Electric foot shock stress-induced exacerbation of alpha-galactosylceramide-triggered apoptosis in mouse liver. Hepatology 2004; 39: 1131-1140

Chida Y, Sudo N, Kubo C. Does stress exacerbate liver diseases? J Gastroenterol Hepatol 2006; 21: 202-208

Chrousos GP. Regulation and dysregulation of the hypothalamic-pituitary-adrenal axis. The corticotropinreleasing hormone perspective. Endocrinol Metab Clin North Am 1992; 21: 833-858

Cronstein BN, Kimmel SC, Levin RI, Martiniuk F, Weissmann G. A mechanism for the antiinflammatory effects

Culman J, Tschope C, Jost N, Itoi K, Unger T. Substance P and neurokinin A induced desensitization to cardiovascular and behavioral effects: evidence for the involvement of different tachykinin receptors. Brain Res 1993; 625: 75-83.

Faunce DE, Sonoda KH, Streilein JS. MIP-2 recruits NKT cells to the spleen during tolerance induction. J. Immunol. 2001; 166: 313-21.

Glaser, R., 2005. Stress-associated immune dysregulation and its importance for human health: a personal history of psychoneuroimmunology. Brain Behav. Immun. 17, 321-328.

Glaser, R., Kiecolt-Glaser, J.K., 2005. Stress-induced immune dysfunction: implications for health. Nat. Rev. Immunol. 5, 243-251.

Hinson JP. Paracrine control of adrenocortical function: a new role for the medulla? J Endocrinol 1990; 124: 7-9.

Hirano T, Akira S, Taga T, Kishimoto T. Biological and clinical aspects of interleukin 6. Immunol Today 1990; 11: 443-449.

Iwakabe K, Shimada M, Ohta A, Yahata T, Ohmi Y, Habu S, and Nishimura T. The restraint stress drives a shift in Th1/Th2 balance toward Th2-dominant immunity in mice. Immunol Lett 62: 39-43, 1998.

Jessop DS, Chowdrey HS, Larsen PJ, Lightman SL. Substance P: multifunctional peptide in the hypothalamopituitary system? J Endocrinol 1992; 132: 331-337.

Kawakami K, Kinjo Y, Uezu K et al. Monocyte chemoattractant protein-1-dependent increase of $\mathrm{V}$ alpha $14 \mathrm{NKT}$ cells in lungs and their roles in Th1 response and host defense in Cryptococcal infection. J. Immunol. 2001; 167: 6525-32.

Karalis K, Sano H, Redwine J, Listwak S, Wilder RL, Chrousos GP. Autocrine or paracrine inflammatory actions

Kelley, K.W., Weigent, D.A., Kooijman, R., 2007. Protein hormones and immunity. Brain Behav. Immun. 21, 384-392.

Kemeny ME, Schedlowski M. Understanding the interaction between psychosocial stress and immune-related diseases: A stepwise progression. Brain, Behavior, and Immunity 21 (2007) 1009-1018. 
Kunkel EJ, Kim JS, Hann HW, Oyesanmi O, Menefee LA, Field HL, Lartey PL, Myers RE. Depression in Korean immigrants with hepatitis B and related liver diseases. Psychosomatics 2000; 41: 472-480.

Larsen PJ, Jessop D, Patel H, Lightman SL, Chowdrey HS. Substance P inhibits the release of anterior pituitary adrenocorticotrophin via a central mechanism involving corticotrophin-releasing factor-containing neurons in the hypothalamic paraventricular nucleus. J Neuroendocrinol 1993; 5: 99-105.

Liao J, Keiser JA, Scales WE, Kunkel SL, and Kluger MJ. Role of corticosterone in TNF and IL-6 production in isolated perfused rat liver. Am J Physiol Regulatory Integrative Comp Physiol 268: R699-R706, 1995.

Lux G, Hagel J, Backer P et al. Acupuncture inhibits vagal gastric acid secretion stimulated by sham feeding in healthy subjects. Gut 1994; 35: 1026-9.

Malarkey, W.B., Mills, P.J., 2007. Endocrinology: the active partner in PNI research. Brain Behav. Immun. 21, 161-168.

Marsland AL, Cohen S, Rabin BS, Manuck SB. Trait positive affect and antibody response to hepatitis B vaccination. Brain Behav Immun 2006; 20: 261-269

Muzaffar L Gill, Muslim Atiq, Syma Sattar And Nasir Khokhar. Psychological implications of hepatitis C virus diagnosis. Journal of Gastroenterology and Hepatology (2005) 20, 1741-1744 of corticotropin-releasing hormone in vivo. Science 1991; 254: 421423.

Nagano J, Nagase S, Sudo N, Kubo C. Psychosocial stress, personality, and the severity of chronic hepatitis $\mathrm{C}$.

Psychosomatics 2004; 45: 100-106

Sanders, V.M., Kavelaars, A., 2007. Adrenergic regulation of immunity. In: Ader, R., Felten, D.L., Cohen, N. (Eds.), Psychoneuroimmunology. Academic Press, New York.

Sawchenko PE, Imaki T, Potter E, Kovacs K, Imaki J, Vale W. The functional neuroanatomy of corticotropin-releasing factor. Ciba Found Symp 1993; 172: 5-21.

Schafer M, Carter L, Stein C. Interleukin 1 beta and corticotropin-releasing factor inhibit pain by releasing opioids from immune cells in inflamed tissue. Proc Natl Acad Sci U S A. 1994 May 10;91(10):4219-23.

Shimizu T, Kawamura T, Miyaji C et al. Resistance of extrathymic T cells to stress and the role of endogenous glucocorticoids in stress associated immunosuppression. Scand. J. Immunol. 2000; 51: 285-92.

Swain MG, Patchev V, Vergalla J, Chrousos GP, and Jones EA. Suppression of hypothalamic-pituitary-adrenal axis responsiveness to stress in a rat model of acute cholestasis. J Clin Invest 91: 1903-1908, 1993.

Swain MG, Appleyard C, Wallace J, Wong H, and Le T. Endogenous glucocorticoids released during acute toxic liver injury enhance hepatic IL-10 synthesis and release. Am J Physiol Gastrointest Liver Physiol 276: G199-G205, 1999.

Swain MG. Stress and the liver. Am J Physiol Gastrointest Liver Physiol 279:1135-1138, 2000.

Tamada K, Harada M, Abe K, Li T, Nomoto K. IL-4-producing NK1.1+ T cells are resistant to glucocorticoidinduced apoptosis: implications for the Th1/Th2 balance. J Immunol 1998; 161: 1239-1247

Tjandra K, Sharkey KA, and Swain MG. Progressive development of a Th1-type hepatic cytokine profile in rats with experimental cholangitis. Hepatology 31: 280-290, 2000 . 
Turnbull AV and Rivier CL. Regulation of the hypothalamicpituitary-adrenal axis by cytokines: actions and mechanisms of action. Physiol Rev 70: 1-71, 1999.

Zachariae R. Hypnosis and immunity. In: Ader R, Felten DL, Cohen N, eds. Psychoneuroimmunology, vol. 2. San Diego: Academi, 2001; 133-60.

Zajac BA, West DJ, McAleer WJ, Scolnick EM. Overview of clinical studies with hepatitis B vaccine made by recombinant DNA. J Infect 1986;13:39-45.

Wang H, Yu M, Ochani $\mathrm{M}$ et al. Nicotinic acetylcholine receptor a7 subunit is an essential regulator of inflammation. Nature 2003; 421: 384-8. 


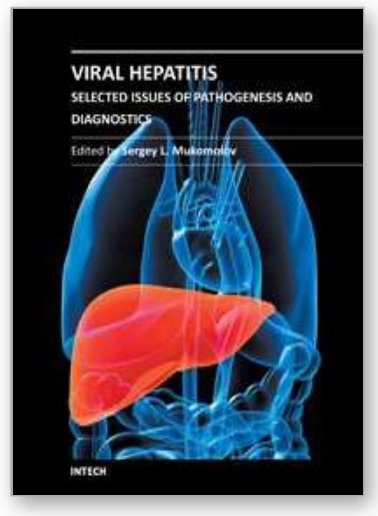

\author{
Viral Hepatitis - Selected Issues of Pathogenesis and Diagnostics \\ Edited by Dr. Sergey Mukomolov
}

ISBN 978-953-307-760-4

Hard cover, 152 pages

Publisher InTech

Published online 07, November, 2011

Published in print edition November, 2011

There are a lot of important issues related to viral hepatitis studies: molecular biology of viruses, laboratory diagnostics, epidemiology, treatment etc. However, there is a number of special textbooks and monographs on the subject. Considering this fact and rather fast progress in our understanding of the problem this book focuses on the important sections of the problem immune pathogenesis of parenterally transmitted viral hepatitis and some aspects of hepatitis diagnostics. Seven chapters were prepared by several groups of researchers to share information and results of studies with specialists working in the field and persons who are interested to learn about the viral hepatitis issue. The Nobel Prize Committee (the field of physiology and medicine, 2011) awarded Bruce A. Beutler and Jules A. Hoffmann for their discoveries concerning the activation of innate immunity whilst Ralph M. Steinman was awarded for his discovery of the dendritic cell and its role in adaptive immunity. We are proud to say that our book is in line with these discoveries, because 3 chapters cover the problems of innate and adaptive immune response in case of viral hepatitis.

\title{
How to reference
}

In order to correctly reference this scholarly work, feel free to copy and paste the following:

Cristin Constantin Vere, Costin Teodor Streba, Ion Rogoveanu, Alin Gabriel Ionescu and Letitia Adela Maria Streba (2011). Evolution of Viral Hepatitis: Role of Psychosocial Stress, Viral Hepatitis - Selected Issues of Pathogenesis and Diagnostics, Dr. Sergey Mukomolov (Ed.), ISBN: 978-953-307-760-4, InTech, Available from: http://www.intechopen.com/books/viral-hepatitis-selected-issues-of-pathogenesis-anddiagnostics/evolution-of-viral-hepatitis-role-of-psychosocial-stress

\section{INTECH}

open science | open minds

\section{InTech Europe}

University Campus STeP Ri

Slavka Krautzeka 83/A

51000 Rijeka, Croatia

Phone: +385 (51) 770447

Fax: +385 (51) 686166

www.intechopen.com

\section{InTech China}

Unit 405, Office Block, Hotel Equatorial Shanghai

No.65, Yan An Road (West), Shanghai, 200040, China 中国上海市延安西路65号上海国际贵都大饭店办公楼 405 单元

Phone: +86-21-62489820

Fax: +86-21-62489821 
(C) 2011 The Author(s). Licensee IntechOpen. This is an open access article distributed under the terms of the Creative Commons Attribution 3.0 License, which permits unrestricted use, distribution, and reproduction in any medium, provided the original work is properly cited. 